\title{
Álcool e drogas no trabalho: conhecimento do candidato ao título de especialista em medicina do trabalho em relação ao tema
}

\author{
Alcohol and drug use at work: required knowledge for the \\ title of specialist in occupational medicine
}

Francisco Cortes Fernandes', João Anastácio Dias'

\begin{abstract}
RESUMO | Contexto: O conhecimento teórico do médico do trabalho em relação ao gerenciamento dos casos de uso, abuso e dependência de álcool e drogas no local de trabalho é um fator preocupante, tendo em vista o grande crescimento desta prática no Brasil. Objetivos: O presente artigo visa avaliar o conhecimento dos médicos do trabalho sobre o tema, objetivando ações de melhoria nesta área de atuação. Tais ações podem ser realizadas pelos cursos de formação e por instituições ligadas à área. Métodos: Foi realizada uma questão aberta em relação ao tema na Prova de Título de Especialista em Medicina do Trabalho de 2012, cujos resultados foram estudados e discutidos através de metodologia de correção desenvolvida pelos autores. Resultados: A média de conhecimento sobre o tema ficou em 4,26, em uma escala de 0 a 10 . Conclusões: $O$ estudo sugere que o conhecimento pericial sobre o tema é precário, exigindo urgentemente ações das instituições formadoras e demais órgãos em relação a este grande problema que ocorre na prática diária. Palavras-chave I etanol; drogas ilícitas; trabalho; gerência.
\end{abstract}

ABSTRACT I Context: Theoretical knowledge of an occupational physician about the management of cases of use, abuse and dependence on alcohol and drugs in the workplace is a concern. This is especially true in light of the strong growth of this problem in Brazil. Objectives: This article aims to assess physicians' knowledge on the subject to help identifyareas for improvement. Such improvements can be attained by training courses and/or participating in institutions related to the field. Methods: An open question on the topic was included in the Test for Certification in Occupational Medicine, 2012, the results of which have been studied and discussed using a correction methodology developed by the authors. Results: The average knowledge on the subject was 4.26 on a scale from $0-10$. Conclusions: The study suggests that the expert knowledge on the subject matter is precarious, requiring urgent educational actions from institutions and other bodies in relation to this major problem that occurs in daily practice.

Keywords I ethanol; street drugs; work; management. 


\section{INTRODUÇÃO}

O uso de substâncias psicoativas tem acompanhado toda a história da humanidade, podendo, dependendo do contexto, ser inofensivo, causar poucos riscos ou assumir padrões de utilização altamente disfuncionais. Nesse contexto, o padrão de consumo pode variar do uso de drogas, ao abuso de drogas e dependência ${ }^{1}$.

A discussão sobre o uso de álcool vem sendo feita pela Organização Mundial de Saúde, reconhecendo-se que é o maior fator de risco para o baixo nível global de saúde e o terceiro fator de risco de mortes prematuras e de incapacidade laboral ${ }^{2}$.

A Associação Nacional de Medicina do Trabalho (ANAMT) elaborou um consenso em relação às competências necessárias ao profissional que exerce esta especialidade. Dentre elas, observa-se a existência da formulação e implementação de políticas e gestão da saúde no trabalho, fato que leva à necessidade de o médico do trabalho saber gerenciar esse importante fator de risco, que pode estar associado ao trabalho ${ }^{3}$.

A gestão das questões relacionadas a álcool e drogas no local de trabalho foi alvo de uma publicação da Organização Internacional do Trabalho (OIT) ${ }^{4}$, na qual são traçadas diretrizes práticas a esse respeito. Estas têm por objetivo orientar a tomada de decisões referente ao problema, não substituindo as normas dos países onde são adotadas. Entre os pontos essenciais, destacam-se:

- As políticas e os programas devem promover a prevenção, a redução e o tratamento dos problemas relacionados ao consumo de álcool e drogas no local de trabalho;

- os problemas relacionados ao consumo devem ser considerados como problemas de saúde, sendo tratados sem discriminação;

- os empregadores, empregados e representantes devem avaliar conjuntamente os efeitos do consumo, cooperando para a elaboração de uma política para a empresa;

- o empregador deve aplicar restrições ou proibições idênticas ao álcool e às drogas, em todos os níveis;

- os programas de saúde da empresa devem ser integrados a programas de informações, instrução e qualificação sobre álcool e drogas;

- os empregadores devem instituir um caráter confidencial a toda informação relacionada ao consumo dessas substâncias;
- as análises toxicológicas para determinar o consumo de álcool e drogas no âmbito do trabalho apresentam problemas éticos, morais e jurídicos, sendo importante discuti-los na oportunidade de sua realização;

- emprego e estabilidade são importantes fatores de recuperação, sendo o local de trabalho uma ajuda para as pessoas com esse problema;

- deve-se reconhecer que o empregador tem autonomia para sancionar os trabalhadores cuja conduta profissional imprópria tenha consequências devido ao consumo de álcool e drogas. Deve-se, contudo, ser dada preferência ao aconselhamento, tratamento e reabilitação, em vez de sanções.

- o empregador deve aplicar o princípio da não discriminação aos trabalhadores que consomem álcool e drogas.

Após avaliar a implementação dessas diretrizes, a OIT concluiu que, se forem adequadamente implementados e desenvolvidos, os programas de prevenção do abuso de substâncias nos locais de trabalho podem ser benéficos para os trabalhadores e empregadores, contribuindo para a formação de uma força de trabalho mais saudável, com moral elevada e para a imagem positiva da empresa perante a comunidade, além de proporcionar maior produtividade ${ }^{5}$.

A ANAMT realiza há aproximadamente 35 anos a prova para obtenção do Título de Especialista em Medicina do Trabalho. Tal prova consta atualmente de cinco questões dissertativas e 50 questões de múltipla escolha, sendo aprovado o candidato que atingir determinada nota e cumprir exigências curriculares específicas da associação. A prova é elaborada por uma comissão de especialistas indicados pelo diretor do Título da Especialista da associação, sendo homologado pela Associação Médica Brasileira (AMB).

\section{OBJETIVOS}

Preocupada com o aumento dos problemas decorrentes do uso de álcool e drogas no local de trabalho, a comissão da prova de 2012 resolveu desenvolver uma metodologia que pudesse medir indiretamente os ensinamentos ministrados nos cursos de especialização e residências médicas em relação a este item, bem como obter uma amostra do conhecimento dos médicos do trabalho em relação ao assunto, objetivando ações para a melhoria neste campo de atuação. 
Assim, o presente trabalho pretendeu avaliar o conhecimento sobre o tema das drogas e álcool no trabalho, e seu gerenciamento, em uma amostra importante de médicos do trabalho, candidatos à obtenção do título de especialista na área. De posse desse conhecimento, a associação poderá direcionar temas de seus congressos e implementar ações nos cursos acreditados pela ANAMT, bem como em residências médicas, objetivando melhorar as competências exigidas para o exercício da medicina do trabalho.

\section{MÉTODOS}

Ao serem elaboradas as questões descritivas da prova de título de especialista realizada em Goiânia, em maio de 2012, foi incluída a seguinte questão: "Como gestor do Programa de Controle Médico de Saúde Ocupacional (PCMSO) de uma grande empresa, como você trabalharia o problema do álcool e drogas no trabalho?".

O conhecimento dos candidatos sobre o tema seria avaliado a partir das respostas obtidas, de acordo com o gabarito abaixo descrito, obtendo dados em relação ao conhecimento que foram discutidos a seguir.

O gabarito da resposta foi baseado nas diretrizes propostas pela OIT, conforme referência citada na introdução, sendo resumido em tópicos para fins de correção, além de sofrer adaptações necessárias à realidade brasileira atual. Tiraria nota máxima na questão o candidato que desenvolvesse corretamente o assunto, abrangendo os seguintes tópicos:

1. Elaboração de uma política da empresa em relação ao uso de álcool e drogas que abrangesse itens de prevenção, redução e tratamento;

2. elaboração de um programa de saúde em relação ao uso de álcool e drogas, contemplando os itens abaixo citados;

3. trata-se de um problema de saúde;

4. não deve haver discriminação;

5. o assunto deve ser tratado com confidencialidade;

6. o programa deve abranger todos os níveis hierárquicos dentro da organização;

7. a empresa deve proporcionar o retorno ao trabalho;

8. o retorno ao trabalho é um fator de ajuda e tratamento ao paciente;

9. estabilidade de emprego;
10. análises toxicológicas são um assunto ainda bastante controverso no Brasil, mas o candidato deve saber que elas existem e são usadas por muitas empresas no país.

A nota variava entre 0 a 10, de acordo com o conteúdo respondido pelo candidato. Para haver uma correção uniformizada, foi elaborado um checklist de avaliação ${ }^{6}$ no qual foram lançados os tópicos que deveriam ser desenvolvidos pelo candidato. Em cada tópico, a nota poderia ser de 0 a 10, de acordo com o Quadro 1, que demonstra o checklist e os critérios de pontuação.

A seguir, explicita-se o conhecimento desejado a ser demonstrado sobre cada item disposto no Quadro 1.

- Item 1: Política: o candidato demonstrou conhecimento em relação à necessidade de ser estabelecida uma política na empresa que deve promover a prevenção, a redução e o tratamento do problema relacionado ao consumo dessas substâncias? Referiu ainda que a política deveria contemplar a participação de empregados e empregadores?

- Item 2: Problema de saúde: o candidato demonstrou entender o uso dessas substâncias como sendo um problema de saúde?

- Item 3: Análises toxicológicas: o candidato demonstrou conhecer este instrumento e as controvérsias sobre seu uso hoje no Brasil?

- Item 4: Estabilidade: o candidato demonstrou entender que a estabilidade no emprego é um fator importante e que facilita a recuperação?

- Item 5: Tratamento médico: o candidato demonstrou entender a necessidade de disponibilizar tratamento médico, quando indicado?

- Item 6: Não discriminar: o candidato conhece seu papel de não discriminar os empregados com esse tipo de problema?

- Item 7: Confidencialidade: o candidato entende a necessidade de confidencialidade em relação ao assunto?

- Item 8: Programa contempla as políticas: o programa em relação a álcool e drogas contempla todos os itens da política? O candidato demonstrou entender a necessidade do cumprimento da política na elaboração do programa?

- Item 9: Atinge todos os níveis hierárquicos: o candidato demonstrou entender a necessidade de o programa atingir todos os níveis hierárquicos da empresa? 
Quadro 1. Critérios utilizados para correção.

\begin{tabular}{|l|l|l|l|}
\hline Conhecimento & \multicolumn{2}{|c|}{ Realizado adequadamente } & Não realizado \\
\hline Nota & $1-3$ & $4-6$ & $7-10$ \\
\hline 1. Política \\
\hline 2. Problema de saúde \\
\hline 3. Análise toxicológica \\
\hline 4. Estabilidade \\
\hline 5. Tratamento médico \\
\hline 6. Não discriminar \\
\hline 7. Confidencialidade \\
\hline 8. Programa contempla as políticas \\
\hline 9. Atinge todos os níveis hierárquicos da empresa \\
\hline 10. Proporciona retorno ao trabalho \\
\hline Total geral \\
\hline
\end{tabular}

- Item 10: Proporcionar retorno ao trabalho: o candidato demonstrou conhecer seu papel como promotor de retorno ao trabalho do empregado?

Os resultados foram obtidos entre a população dos médicos inscritos para a prova do título de especialista realizado em Goiânia, em 2012, totalizando 106 pessoas.

\section{RESULTADOS}

A média de notas da população ficou em 4,26, dentre um resultado possível de 0 a 10 , e moda 4 . A maior nota foi 10; a menor, 0 .

$\mathrm{O}$ item com maior quantidade de acertos foi o 5 , com 101 candidatos referindo a necessidade de tratamento. O segundo item mais acertado foi $\mathrm{o} 2$, em relação ao conceito do uso de álcool e drogas com um problema de saúde, com 98 candidatos citando esse fato.

Os itens com menor número de acertos foram o 1 , sobre a elaboração de uma política de prevenção, redução e tratamento, citado por apenas 24 dos candidatos, e o 3 , sobre a realização de testes, citado por apenas 16 dos candidatos.

\section{CONCLUSÃO}

A população do estudo é formada por candidatos ao título de médico do trabalho conferido pela ANAMT/AMB, pressupondo-se um nível de conhecimento maior da especialidade. O gerenciamento deste problema por parte do especialista em medicina do trabalho deve constar da prática diária, presumindo-se um entendimento grande sobre o tema.

Avaliando-se a média das notas, estabelecida entre 3,20 e 5,32 para aproximadamente $70 \%$ dos candidatos, os resultados demonstraram o baixo nível de conhecimento teórico dos participantes. Pressupõe-se, assim, a necessidade de os formadores atuarem de forma mais efetiva na propagação desses conceitos, objetivando um entendimento mais adequado das atribuições do médico do trabalho e proporcionando o desempenho adequado desta competência técnica. Do mesmo modo, a ANAMT poderia divulgar orientações sobre o problema, contribuindo para aprimorar a excelência dos médicos do trabalho.

Finalmente, a metodologia descrita neste estudo poderia ser utilizada nas próximas provas, visando medir o nível de conhecimento dos candidatos sobre assuntos considerados importantes pela associação. 


\section{REFERÊNCIAS}

1. Serviço Social da Indústria. Prevenção ao uso de álcool e outras drogas no ambiente de trabalho: conhecer para ajudar. Brasília: Secretaria Nacional Antidrogas; 2008. p. 40-49. [acesso em 30 abr. 2013]. Disponível em: <http://crruece.woese.com/upload/ ca2411c631dd856f9d35eae6537d59e3.pdf>

2. World Health Organization. Global strategy to reducetheharmful use of alcohol. Geneva: WHO;2010. [acesso em 20 mar.2013]. Disponível em: <http://www.who.int/substance_abuse/alcstratenglishfinal.pdf>

3. Associação Nacional de Medicina do Trabalho. Competências essenciais requeridas para o exercício da medicina do trabalho. Centro de Estudos Avançados sobre as práticas da Medicina do Trabalho - CEAMT; 2003.
4. Organização Internacional do Trabalho.Gestão das questões relacionadas com o álcool e drogas nos locais de trabalho. Genebra: OIT; 2008.

5. Organização Internacional do Trabalho. Problemas ligados ao álcool e a drogas no local de trabalho: uma evolução para a prevenção. Genebra: OIT; 2008.

6. Tibério IFLC, Daud-Gallotti RM, Troncon LEA, Martins MA (eds.). Avaliação Prática de Habilidades Clínicas em Medicina. São Paulo: Atheneu; 2012.

Endereço para correspondência: Francisco Cortes Fernandes - Rua Martim Francisco, 53, apto. 32 - CEP: 09541-330 - São Caetano do Sul (SP), Brasil -

E-mail: francisco cortes fernandes@yahoo.com.br 